\title{
Gambaran Analisa Gas Darah pada Distres Pernapasan
}

\author{
Srie Yanda
}

Distres pernapasan merupakan salah satu problem yang mengancam jiwa. Analisis gas darah arteri (AGDA) penting untuk menentukan tata laksana distres pernapasan, seperti menegakkan diagnosis, menentukan terapi, maupun untuk evaluasi setelah mendapat terapi. Namun interpretasinya harus dilakukan bersamaan dengan penilaian klinis. Kelainan AGDA oleh karena gangguan pernapasan dapat berupa asidosis respiratorik (pada gangguan paru restriktif), alkalosis respiratorik (pada gangguan paru obstruktif) dan asidosis campuran (pada penyakit paru dengan komplikasi). Prinsip umum tata laksana distres pernapasan ditujukan kepada penyakit utamanya. Perhatian harus ditujukan pada perbaikan volume ekstraselular, koreksi elektrolit, menghilangkan zat toksik, dan memperbaiki ventilasi.

Kata kunci: analisis gas darah arteri, distres pernapasan.

$\mathscr{A}$ nalisis gas darah arteri AGDA merupakan "baku emas" untuk menilai adekuasi oksigenasi dan ventilasi, merupakan bagian penting dalam diagnosis serta penatalaksanaan gangguan oksigenasi dan asam basa. ${ }^{1,2}$ Analisis gas darah arteri yang abnormal mungkin merupakan petunjuk pertama problem asam-basa atau oksigenasi dan akan membantu penentuan terapi yang sesuai dan efektif ${ }^{2}$

Distres pernapasan merupakan salah satu keluhan utama tersering pada anak yang memerlukan perawatan rnedis, dan salah satu problem yang mengancam jiwa tersering selain gangguan perfusi perifer dan penurunan kesadaran. ${ }^{3,4}$ Distres pernapasan merupakan 10\% dari semua keluhan Bagian Gawat Darurat Anak, 20\% di antaranya berusia $<2$ tahun. Lebih kurang 5\% dari kematian pada anak $<15$ tahun dan 29\% pada bayi disebabkan oleh proses gangguan pernapasan primer. Distres pernapasan juga dapat menyebabkan kematian pada penderita dengan gangguan primer pada sistem lainnya. ${ }^{3}$ Anammesis dan pemeriksaan fisis me-

Alamat korespondensi:

Dr. Srie Yanda, Sp.A.

Bagian Ilmu Kesehatan Anak FK-USU/RSUP H. Adam Malik Medan.

Jl. Bunga Lau no. 17, Medan.

Tel (061)8361721, Fax (061)8361721. rupakan langkah pertama terpenting untuk diagnosis. Analisis gas darah arteri merupakan uji fungsi paru yang sangat bermanfaat, tetapi interpretasinya harus bersamaan dengan penilaian klinis. ${ }^{5,6}$

Tujuan tulisan ini adalah menerangkan tentang patofisiologi pernapasan, distres pernapasan, analisis gas darah pada distres pernapasan, dan penatalaksanaannya.

\section{Patofisiologi Pernapasan}

Sistem pernapasan terdiri dari (1) mekanisme pompa, (2) membran pertukaran gas, dan (3) kontrol saraf pusat. Dasar dari pengaturan ini adalah keseluruhan fungsi pernapasan dan sirkulasi yang menjamin tidak hanya efisiensi pertukaran gas tetapi juga kemampuan beradaptasi dengan kebutuhan hidup lainnya. Perubahan komponen sistem pernapasan atau interaksinya dengan sistem sirkulasi menyebabkan berbagai manifestasi klinis. Manifestasi terberat yang tersering adalah abnormalitas $\mathrm{PaO}_{2}$ dan $\mathrm{PaCO}_{2}$ yang dikenal sebagai gagal napas. ${ }^{7}$

Penyakit paru restriktif terjadi bila tekanan permukaan abnormal tinggi (sindrom distres pernapasan pada neonatus) struktur atau komposisi bagian padat paru berubah (edema interstistal, pneumonitis, fibrosis) atau ruang alveolar dipenuhi 
dengan cairan atau sel-sel inflamasi yang membatasi pengembangan paru (edema alveolar, pneumonia). Penyakit dinding dada restriktif biasanya disebabkan anomali struktur dinding dada (skoliosis atau distrofi iga), penyakit neuromaskular, atau distensi perut. ${ }^{4,7}$

Pada penyakit paru obstruktif ekstratoraks (croup, benda asing, epiglotitis, tonsil dan adenoid sangat besar) dan intratoraks (asma, trakeobronkomalasia, bronkiolitis, benda asing, vascular ring) terjadi perubahan ukuran saluran napas yang berlebihan. ${ }^{4,7}$ Pemeriksaan fisis yang dilakukan dengan teliti dapat memberikan informasi untuk menentukan seorang anak menderita penyakit paru restriktif atau obstruktif (Tabel $\mathbf{1}$ ). kesadaran merupakan tanda stadium progesif gagal napas. ${ }^{9}$

Pendekatan diagnostik terhadap anak dengan distres pernapasan, yang harus dinilai pertama kali adalah adekuasi oksigenasi (pemindahan oksigen yang adekuat dari alveoli ke dalam darah, terutama dalam bentuk oksihemaglobin) dan ventilasi (pergerakan volume udara ke dalam dan ke luar paru, mengeluarkan $\mathrm{CO}_{2}$ dari darah dan menyediakan $\left.\mathrm{O}_{2}\right)^{3,11}($ Tabel 2)

\section{Analisis Gas Darah pada Distres Pernapasan}

Paru mempunyai fungsi utama untuk melakukan

Tabel 1. Karakteristik Klinis Penyakit Paru Restriktif dan Obstruktif pada Anak

\begin{tabular}{|c|c|c|c|}
\hline \multirow[t]{2}{*}{ Parameter } & \multirow[t]{2}{*}{ Penyakit restriktif } & \multicolumn{2}{|c|}{ Penyakit obstruktif } \\
\hline & & Ekstratoraks & Intratoraks \\
\hline Frekuensi pernapasan & $\pi$ & $k$ & $\mathrm{~N}$ atau $\boldsymbol{K}$ \\
\hline Durasi inspirasi & $k$ & $\pi$ & Tidak berubah \\
\hline Durasi ekspirasi & $k$ & Tidak berubah & $\pi$ \\
\hline Otot pernapasan asesoris & Inspirasi & Inspirasi & $\begin{array}{l}\text { Inspirasi \& ekspirasi } \\
\text { (abdominal) }\end{array}$ \\
\hline Distorsi (retraksi) iga & + & + & Sering + \\
\hline Amplitudo gerakan napas & Dangkal & $\mathrm{N}$ atau $K$ & $\mathrm{~N}$ atau $\boldsymbol{K}$ \\
\hline Auskultasi & Crackles & Stridor inspirasi & Wheezing ekspirasi \\
\hline Gambaran radiologis paru & $\begin{array}{l}\boldsymbol{K} \text { volume paru } \\
\text { Densitas alveolar }\end{array}$ & $\mathrm{N}$ & $\lambda$ volume paru \\
\hline
\end{tabular}

Dikutip dari Fontan JJP dan Jenson $\mathrm{HB}^{7}$. dengan modifkasi

\section{Distres Pernapasan}

Distres pernapasan disebabkan oleh disfungsi atau pemutusan jalur respirasi/ventilasi dan/atau sistem yang mengontrol atau mengatur pernapasan. ${ }^{3}$ Bila sistem pernapasan tidak mampu mempertahankan ambilan $\mathrm{O}_{2}$ atau eliminasi $\mathrm{CO}_{2}$ secara seimbang dengan kebutuhan metabolik, terjadi insufisiensi pernapasan ypengaruhi sistem neuromuskular dinding dada. ${ }^{4,8}$

Dua stadium insufisiensi pernapasan dapat dikenali. Pada stadium awal anak gelisah dan iritabilitas paradoksikal. Peningkatan usaha bernapas, seperti napas cuping hidung dan retraksi interkostal dan subkostal, nyata pada fase ini. Berkurangnya usaha bernapas dan penurunan pertukaran gas, sehingga membuat tekanan gas darah arteri dalam batas tertentu. ${ }^{12}$ Pada gangguan paru restriktif beban kerja pernapasan semakin berat agar dapat mengatasi daya elastik alat pernapasan. Akibat fisiologis ventilasi yang terbatas ini terjadi hipoventilasi alveolar dan tidak adanya kemampuan untuk mempertahankan tekanan gas darah normal. Hipoventilasi dapat menyebabkan asidosis yang terjadi akibat retensi $\mathrm{CO}_{2}$ oleh paru. Peningkatan $\mathrm{PaCO}_{2}$ menimbulkan penurunan $\mathrm{pH} .{ }^{8}$ Sebaliknya, penderita penyakit paru obstruktif secara volunter mengadakan hiperventilasi untuk mengeluarkan lebih banyak $\mathrm{CO}_{2}$. Pada umumnya hiperventilasi menyebabkan alkalosis sebagai akibat dari ekskresi $\mathrm{CO}_{2}$ yang berlebihan dari paru. Hiperventilasi menggambarkan usaha tubuh untuk meningkatkan $\mathrm{PaO}_{2}$ dan usaha membuang kelebihan $\mathrm{CO}_{2}$ dari paru. ${ }^{8}$ 
Sari Pediatri, Vol. 4, No. 3, Desember 2002

Tabel 2. Tanda-tanda distres pernapasan dan ancaman kelelahan.

\begin{tabular}{ll}
\hline Tanda klinis & Pemeriksaan fisik \\
\hline Terlihat cemas & $\rightarrow$ dahi berkerut \\
Tanda-tanda aktivitas simpatis berlebihan & $\rightarrow$ pupil dilatasi, dahi berkeringat \\
Dispne & $\rightarrow$ bicara berkurang \\
Penggunaan otot-otot asesoris & $\rightarrow$ menjauhkan kepala dari bantal \\
Mulut terbuka saat inspirasi & $\rightarrow$ menjilat bibir yang kering \\
Tekanan akhir-ekspirasi positif & $\rightarrow$ bibir berkerut, merintih pada saat ekspirasi,mengerang, bibir sianosis \\
Gelisah dan tidak tenang & $\rightarrow$ apatis dan koma \\
\hline
\end{tabular}

Dikutip dari Benumof $\mathrm{JL}^{10}$, dengan modifikasi.

\section{Gangguan Keseimbangan Asam Basa oleh karena Gangguan Pernapasan (Tabel 3)}

\section{Asidosis respiratorik / hipoventilasi alveolar/ hiperkapnia arterial}

Asidosis respiratorik adalah keadaan klinis yang terjadi akibat peningkatan abnormal $\mathrm{PaCO}_{2}$ (hiperkapnia), sehingga terjadi asidemia, yang ditandai dengan $\mathrm{pH}$ gas darah $<7,35$ dan peningkatan $\mathrm{PaCO}_{2}$ primer hal ini disebabkan karena ventilasi alveolar yang tidak efektif. ${ }^{13,14}$ Peningkatan $\mathrm{PaCO}_{2}$ mengakibatkan peningkatan akut $\mathrm{HCO}_{3}$ plasma yang timbul dari mekanisme dasar, tetapi adaptasi ini sangat kecil. ${ }^{13,15}$ Bila terjadi hiperkapnia, konsentrasi $\mathrm{HCO}_{3}$ plasma makin meningkat akibat regulasi dan asidifikasi ginjal. ${ }^{14,15}$ Adaptasi ini membutuhkan 3-5 hari untuk meningkatkan ekskresi asam dan kloruresis sehingga terjadi hiperbikarbonatemia hipokloremik yang khas pada hiperkapnia kronik. ${ }^{14,15}$

\section{Alkalosis respiratorik / hiperventilasi alveolar / hipokapnia arterial}

Alkalosis respiratorik adalah keadaan klinis yang terjadi akibat penurunan abnormal $\mathrm{PaCO}_{2}$ (hipokapnia) sehingga, terjadi alkalemia. ${ }^{13}$ Penurunan $\mathrm{PaCO}_{2}$ primer akan meningkatkan $\mathrm{pH}$ gas darah $>7,45$ disebabkan meningkatnva ventilasi alveolar melebihi produksi $\mathrm{C} 0 \cdot{ }^{13,14,16}$

Penurunan $\mathrm{PaCO}_{2}$ (hipokapnia) menyebabkan dua efek yang bertentangan dalam persamaan asam basa. ${ }^{17}$ Dalam jangka pendek terjadi peningkatan $\mathrm{pH}$ dan penurunan $\mathrm{HCO}_{3}$ plasma akibat dari dapar jaringan, sedangkan dalam jangka panjang, (setelah 6-72 jam) ekskresi asam oleh ginjal akan dihambat, yang mengakibatkan penurunan konsentrasi $\mathrm{HCO} 3$ plasma dan $\mathrm{pH}$ darah. ${ }^{17,18}$

Adanya akalosis respitarorik merupakan tanda prognostik yang buruk karena mortalitas meningkat sebanding dengan proporsi beratnya hipokapnia. ${ }^{19}$

Tabel 3. Kompensasi yang Diharapkan pada Kelainan Asam Basa Primer ${ }^{14}$

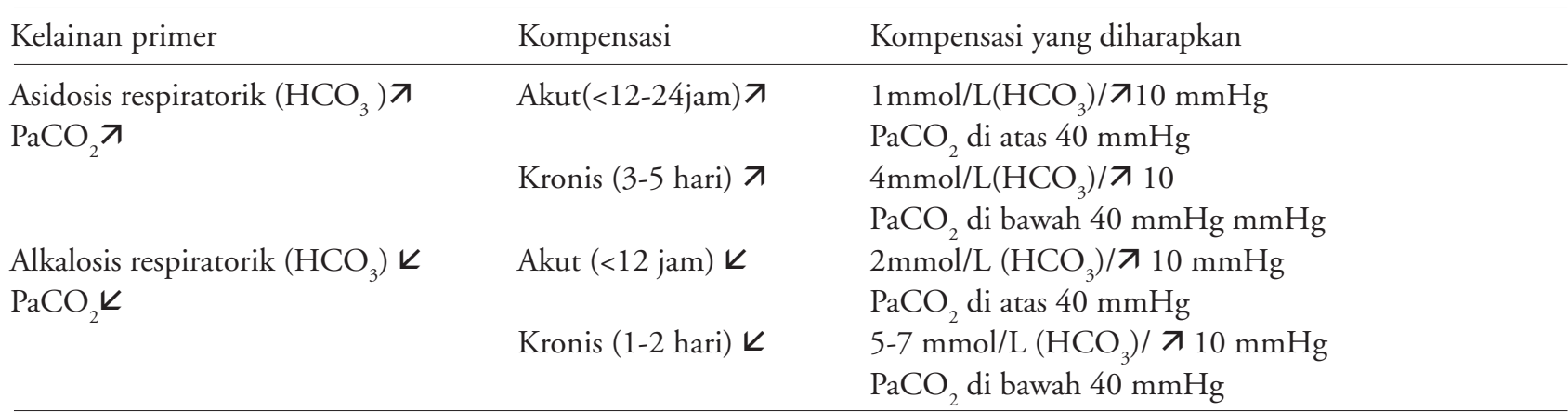

Dikutip dari Brewer ED. ${ }^{14}$ dengan modifikasi. 


\section{Asidosis Campuran}

Kombinasi kelainan gas darah yang penting pada anak sakit akut dan berat adalah campuran asidosis respiratorik dan asidosis metabolik. Komponen metabolik ditunjukkan dengan penurunan base excess (BE) dan komponen respiratorik dengan peningkatan $\mathrm{PaCO}_{2}{ }^{16}{ }^{16}$ Penyakit respirasi mencegah kompensasi dalam penurunan $\mathrm{PaCO}_{2}$, dan komponen metabolik membatasi kemampuan untuk meningkatkan kadar $\mathrm{HCO}_{3}$ plasma, yang akan menormalkan dapar asidosis respiratorik. Pada situasi ini penurunan $\mathrm{pH}$ sering berlebihan, lebih besar daripada gangguan tunggal. ${ }^{20}$

Asidosis campuran dapat diobservasi pada beberapa keadaan klinis, seperti penyakit paru obstruktif menahun dengan komplikasi gagal sirkulasi atau sepsis, edema paru berat, dan lain-lain. ${ }^{15}$

\section{Tata laksana}

Prinsip umum penanggulangan kelainan gas darah ditujukan kepada penyakit utamanya. ${ }^{13,15,19}$ Perhatian ditujukan pada perbaikan volume ekstraselular, koreksi defisiensi $\mathrm{K}$ atau $\mathrm{Cl}$, zat toksik dan memperbaiki ventilasi ${ }^{15}$ (Tabel 4)

\section{Asidosis Respiratorik /Hipoventilasi Alveolar / Hiperkapnia Arterial}

Penatalaksanaan asidosis respiratorik adalah dengan memperbaiki ventilasi alveolar dengan menggunakan ventilasi mekanik dan mengatasi faktor penyebab. ${ }^{13}$
Setiap pasien dengan $\mathrm{PaCO}_{2}$ yang tinggi akan segera kekurangan $\mathrm{O}_{2}$ dan pada kasus apnea harus diperhatikan konsentrasi $\mathrm{HCO}_{3}$. Bila $\mathrm{HCO}_{3}$ normal membuktikan bahwa hal tersebut awitan akut, kompensasi metabolik tidak terjadi, aman untuk memberikan $\mathrm{O}_{2}$ konsentrasi tinggi. Bila konsentrasi $\mathrm{HCO}_{3}$ tinggi secara abnormal menunjukkan bahwa penderita mengalami retensi $\mathrm{CO}_{2}$ jangka panjang pengobatan $\mathrm{O}_{2}$ harus lebih hati-hati. ${ }^{21}$

Usaha pengobatan harus segera difokuskan pada pengamanan saluran napas dan memperbaiki oksigenasi yang adekuat. Ventilasi mekanik harus diberikan bila terjadi apnea, hipoksemia berat yang tidak responsif terhadap tindakan konservatif, atau asidodid respiratorik progresif $\left(\mathrm{PaCO}_{2}>80 \mathrm{mmHg}\right)$. Menit ventilasi harus ditingkatkan sehingga $\mathrm{PaCO}_{2}$ kembali pada keseimbangan asam basa secara bertahap dan ekskresi $\mathrm{HCO}_{3}$ oleh ginjal tercapai. ${ }^{15}$

\section{Alkalosis Respiratorik / Hiperventilasi Alveolar / Hipokapnia Arterial}

Pada sindrom hiperventilasi, dapat digunakan ventilator dengan frekuensi yang dikurangi dan menambah ruang rugi.13 Pada sindrom hiperventilasi-gelisah pendekatan terapi aktif yang memberikan ketenangan, sedasi, dan terutama psikoterapi sangat bermanfaat. Bila alkalemia disebabkan hipokapnia berat dan persisten, pemberian sedasi dibutuhkan. ${ }^{19}$

Obat-obatan hanya terbatas pada pengobatan hiperventilasi simtomatik. $\beta$-blocker bermanfaat untuk menghilangkan simtom simpatis tetapi tidak boleh digunakan bila ada sangkaan sama. Ben-

Tabel 4. Perubahan Gas Darah Disebabkan oleh Pengaturan Ventilator ${ }^{22}$

\begin{tabular}{|c|c|c|c|c|c|}
\hline Kelainan primer & Frekuensi & PIP & PEEP & IT & $\mathrm{FiO}_{2}$ \\
\hline$\pi \mathrm{PaCO}_{2}$ & $k$ & $k$ & $\begin{array}{c}\text { Tidak dapat } \\
\text { digunakan }\end{array}$ & $\begin{array}{c}\text { Tidak dapat } \\
\text { digunakan }\end{array}$ & $\begin{array}{c}\text { Tidak dapat } \\
\text { digunakan }\end{array}$ \\
\hline $\boldsymbol{k} \mathrm{PaCO}_{2}$ & $\pi$ & $\pi$ & $\begin{array}{l}\text { Tidak dapat } \\
\text { digunakan }\end{array}$ & $\begin{array}{l}\text { Tidak dapat } \\
\text { digunakan }\end{array}$ & $\begin{array}{c}\text { Tidak dapat } \\
\text { digunakan }\end{array}$ \\
\hline$\pi \mathrm{PaO}_{2}$ & $\begin{array}{l}\text { Tidak dapat } \\
\text { digunakan }\end{array}$ & $\pi$ & $\pi$ & $\pi$ & $\pi$ \\
\hline$K \mathrm{PaO}_{2}$ & $\begin{array}{l}\text { Tidak dapat } \\
\text { digunakan }\end{array}$ & $k$ & $k$ & $\begin{array}{c}\text { Tidak dapat } \\
\text { digunakan }\end{array}$ & $k$ \\
\hline
\end{tabular}

Dikutip dari Gomela TC, Cunningham MD, Eyal FG.22 dengan modifikasi, b = pada edem paru berat \& perdarahan paru, $\boldsymbol{\nearrow}$ PEEP dapat menyebabkan $\ll \mathrm{PaCO} 2, \mathrm{c}=$ tidak digunakan jika I $: \mathrm{E}$ tidak berlebihan, $\mathrm{PIP}=$ peak inspiratory pressure (tekanan inspirasi puncak), $\mathrm{PEEP}=$ positive end-expiratory pressure (tekanan akhir-ekspirasi positive), IT = inspiratory time (waktu inspirasi) 
zodiazepin mengurangi keluhan subjektif, tetapi efek jangka panjang belum dapat dibuktikan dan kemungkinan adiktif membatasi penggunaan jangka lama. Monoamine oxidase inhibitor seperti antidepresan trisiklik, dapat diberikan pada pasien dengan ansietas panik dan simtom autonom multipel. klomipramin dan imipramin dapat membantu menormalkan $\mathrm{PaCO}_{2}$ pada penderita yang panik. ${ }^{18}$

\section{Asidosis campuran}

Efek aditif pada asidemia dari hiperkapnia dan defisit bikarbonat, dapat menyebabkan asidemia yang nyata yang membutuhkan terapi segera. Terapi harus ditujukan terhadap penyebab spesifik.2 Bila mungkin, pengobatan harus ditargetkan pada kedua komponen asidosis campuran. ${ }^{15}$

Asidosis campuran dikoreksi dengan memperbaiki ventilasi untuk memberikan $\mathrm{O}_{2}$ dan menurunkan $\mathrm{PaCO}_{2}$, memperbaiki cairan dan obatvasoaktif untuk memperbaiki perfusi sistemik. Sodium bikarbonat $\left(\mathrm{NHCO}_{3}\right)$ bukan obat resusitasi first line, pemberian $\mathrm{NHCO}_{3}$ pada asidosis berat masih kontroversial. ${ }^{6}$

\section{Ringkasan}

Gambaran AGDA pada distres pernapasan terdiri dari (1) asidosis respiratorik, terjadi hipoventilasi alveolar yang menyebabkan hiperkapnia arterial, (2) alkalosis respiratori terjadi hiperventilasi alveolar yang menyebabkan hipokapnia arterial, dan (3) asidosis campuran. Penatalaksanaan asidosis respiratorik dengan memperbaiki oksigenasi dan mengatasi faktor penyebab. Penatalaksanaan alkalosis respiratorik dengan ventilator dan pemberian obat untuk hiperventilasi simtomatik dan mengatasi faktor penyebab. Sedangkan asidosis campuran dikoreksi dengan memperbaiki ventilasi, memperbaiki cairan, dan pemberian obat vasoaktif natrium bikarbonat bukan first line dan masih kontroversial.

\section{Daftar Pustaka}

1. Durand DJ, Phillips BL. Blood gases: technical aspects and interpretation. Dalam Goldsmith JP, Karotkin EH, penyunting. Asssisted ventilation of the neonate. Edisi ke-5. Philadelphia: WB Saunders, 1996. h. 257-71.

2. Malley WJ. Clinical blood gases, application and noninvasive alternatives. Philadelphia: WB Sounders, 1990. h. 257-78.

3. Weiner DL. Respiratory distress. Dalam: Fleisher GL, Ludwig $S$, penyunting. Textbook of pediatric emergency medicine. Edisi ke-4. Philadelphia: Lippincott, 2000. h. 553-4.

4. Lister G, Fontan JJP. Pediatric critical care. Dalam: Nelson WE, Behrman RE, Kliegman RM, Arvin AM, penyunting. Nelson textbook of' pediatrics. Edisi ke15. Philadelphia: Saunders, 1996. h. 239-45.

5. Haddad GG, Palazzo RM. Diagnostic approach to respiratory disease. Dalam: Behrman RE, Kliegman RM, Jenson $\mathrm{HB}$, penyunting. Nelson textbook of pediatrics. Edisi ke16. Philadelphia: WB Saunders, 2000. h. 1253-8.

6. Komisi Resusitasi Pediatrik UKK PGD-IDAI. Kumpulan materi pelatihan resusitasi pediatrik tahap lanjut. UKK PGD-IDAI 2002-2003. h. 46-51.

7. Fontan JJP, Haddad GG. Respiratory patophysiology. Dalam: Behrman RE, Kliegman RM, Jenson HB, penyunting. Nelson textbook of pediatrics. Edisi ke-16. Philadelphia: WB Saunders, 2000. h. 1240-8.

8. Wilson LMC. Patofisiologi respirasi. Dalam: Price SA, Wilson LMC, penyunting. Patofisiologi, konsep klinis proses-proses penyakit. Edisi ke-4, buku 1, Alih bahasa: Anugerah P. Jakarta: EGC, 1995. h. 645-719.

9. Haafiz AB, Kissoon N. The critically ill child. Dalam: Singh NC, penyunting. Manual of pediatric critical care. Philadelphia: WB Saunders,1997.h. 1-11.

10. Benumof JL Conventional (laryngoscopic) orotracheal and nasotracheal intubation (single-human type). Dalam: Benumof JL, penyunting. Clinical procedures in anesthesia and intensive care. Philadelphia: Lippincott, 1992. h. 115-9.

11. Williams AJ. ABC of oxygen, assessing and interpreting blood gases and acid- base balance. BMJ 1998; 317:12136.

12. Shneerson J. Respiratory failure. Medicine 1995; 23:380-3.

13. Latief A. Gangguan keseimbangan asam basa Dalam: Trihono PP, Purnamawati S, Syarif DR, Hegar B, Gunardi H, Oswari H, dkk. Hot topics in pediatrics, penyunting. Pendidikan Kedokteran Berkelanjutan Ilmu Kesehatan Anak XLV Jakarta. BL FKUI 2001. h. 146-61

14. Brewer ED. Disorders of acid-base balance. Pediatr Clin North Am 1990; 37:429-47.

15. Adrogue HJ, Madias NE. Management of life-threatening acid-base disorders. N Engl J Med 1998; 338:2634 .

16. Finberg L, Kravath RE, Hellerstein S. Water and elechtrolytes in pediatrics, physiology, pathology and treatment. Edisi ke-2. Philadelphia: Saunders, 1993.

17. Krapf R, Beeler I, Hertner D, Hulter HN, Chronic respiratory alkalosis, the effect of sustained hyperventilation on renal regulation of acid-hase equilibrium $\mathrm{N}$ Engl J Med 1991; 324:1394-401.

18. Gardner WN. The patophysiology of hyperventilation 
disorders. Chest 1996; 109:516-34.

19. Adrogue HJ, Madias NE. Management of life-threatening acid-base disorders. N Engl J Med 1998; 338:107-11.

20. Adelman RD, Solhung MJ. Patophysiology of body fluids mid fluid therapy. Dalam: Nelson WE, Behrman RE, Kliegman RM, Arvin AM, penyunting. Nelson textbook of pediatrics. Edisi ke-15. Philadelphia: Saunders,
1996. h. 200-6.

21. Matthews PC Arterial blood gases and acid base balance. BMJ 1999; 318:734.

22. Gomella TC, Cunningham MD, Eyal FG. Neonatology, management, procedures, on-call problems, diseases and drugs. Edisi ke-3. USA: Appleton \& Lange, 1994. h. 43-69. 